\title{
The therapeutic response of somatotropinomas according to the T2-weighted signal intensity on the MRI
}

1) Iuliu Hatieganu University of Medicine and Pharmacy, Cluj-Napoca, Romania; Emergency County Hospital Alba-Iulia, Alba, Romania

2) Department of Medical Informatics and Biostatistics, Iuliu Hatieganu University of Medicine and Pharmacy, Cluj-Napoca, Romania

3) Department of Endocrinology, Iuliu Hatieganu University of Medicine and Pharmacy, Cluj-Napoca, Clinical Emergency County Hospital, Romania

DOI: $10.15386 / \mathrm{mpr}-1299$

Manuscript received: 17.12 .2020

Received in revised form: 31.03 .2021

Accepted: 12.04.2021

Address for correspondence:

dleucuta@umfcluj.ro

This work is licensed under a Creative Commons Attribution-NonCommercialNoDerivatives 4.0 International License

\section{Carla-Liana Scânteie ${ }^{1}$, Daniel-Corneliu Leucuța ${ }^{2}$, Cristina Ghervan ${ }^{3}$}

\begin{abstract}
Background and aim. Identifying the predictive factors of tumoral and hormonal answer of somatotropinomas to the medical treatment with somatostatin analogs represent an important element for treatment management. The aim of this study was to assess the therapeutic answer of the somatotropinomas according to the T2weighted signal intensity on the MRI.

Methods. We included 31 acromegalic patients, mean age $51.35 \pm 10.37$ years, who underwent surgery. The patients were divided according to the T2-weighted MRI signal intensity - hypointense, hyperintense and isointense - of the GH-secreting pituitary adenoma and were evaluated after surgery, 3, 6 and 12 months with somatostatin analogs therapy.

Results. 16 (51.61\%) somatropinomas were hypointense, 9 (29.03\%) were hyperintense and $6(19.35 \%)$ were isointense. The median IGF-1 and GH level decreased significantly in macroadenomas ( $<<0.001, p<0.001$, respectively), whereas $\mathrm{GH}$ decreased significantly only in microadenomas $(\mathrm{p}=0.010)$. A significant statistical correlation was found between IGF-1 or GH levels and tumor volume before surgery (Spearman $=0.38, \mathrm{p}<0.001$; Spearman $=0.64, \mathrm{p}<0.001$, respectively) and after surgery (Spearman $=0.61, \mathrm{p}=0.001$; Spearman $=0.74, \mathrm{p}<0.001$ ). The percentage of optimally controlled patients increased from $12.9 \%$ after surgery, to $28.57 \%$ after 12 months with somatostatin analogs. The highest percentage of optimally controlled patients with somatostatin analogs treatment was in hypointense somatotropinomas $(50 \%)$.

Conclusion. The T2-weighted MRI signal intensity classifies the somatotropinomas into groups with certain evolutive and medical treatment response particularities, of which we found that the hypointense somatotropinomas have a better therapeutic response after surgery and after long-term treatment with somatostatin analogs.
\end{abstract}

Keywords: acromegaly, T2-weighted MRI, somatostatin analogs, pituitary adenoma

\section{Introduction}

Acromegaly is a rare disfiguring condition of underlying excessive, persistent and autonomous production of GH (growth hormone), and consequently of IGF-1 (insulin-like growth factor-1), secreted in most cases (98\%) by a pituitary adenoma (somatotropinoma) that usually appears as a macroadenoma $(>10 \mathrm{~mm}$ ) on the MRI (magnetic resonance imaging) [1-3].

Somatotropinomas assessment at diagnosis is based on clinical, hormonal and imaging features, thereby highresolution MRI and the OST (acute octreotide suppression test) represent good candidates to characterize and to predict the aggressiveness of this type of adenoma $[2,4]$. Nevertheless, the OST's merits remain uncertain [5]. Therefore, the MRI may become the standardized, noninvasive technique to be used at diagnosis in order to predict the tumor response to treatment. The signal intensity of T2-weighted MRI varies on somatotropinomas, being either hypo-, hyper- or isointense, whereas on 
other types of pituitary adenomas the signal intensity is usually hyperintense (T2-weighted MRI without contrast) [6]. This aspect is very important for further analysis of treatment choice.

It is widely accepted that transsphenoidal surgery represents the gold standard for treating acromegaly, being able to reduce the GH secretion by removing the tumor $[7,8]$; however, the mainstay of medical treatment is represented by SSA (somatostatin analogs), octreotide and lanreotide, which are used as primary, adjuvant or preoperative treatment $[3,4]$. The availability of SSA has improved the effectiveness of medical treatment and helped to acquire a better prognosis in patients with acromegaly [9], the SSA having antisecretory and antiproliferative effects on GH [10].

Various studies demonstrated that the pre-operative treatment with octreotide and lanreotide improved shortterm surgical benefit on macroadenomas [11,12], their efficacy remaining unproven long-term [13]. Other studies pointed out that the T2-weighted signal intensity correlated with the response to SSA treatment and with the histological subtype [14] - most somatotropinomas being hypointense, due to densely granulated pattern, had a better long-term response to SSA, in comparison with those with sparsely granulated adenomas who had a weak response $[6,11,15]$. Even though most of the patients are effectively treated with SSA, one third of them may develop drug resistance, which is due to a reduction in SSR (somatostatin receptor) density or the differentiated expression of the receptors [16]. Thus, it is important to identify the patients resistant to drug therapy in order to initiate therapeutic alternatives and to improve the prediction to medication response, which can modify the stratification of therapeutic management [14].

Given the facts, the aim of this study was to investigate the therapeutic response of somatotropinomas after surgery and after long-term treatment with SSA (1 year) taking into consideration the T2-weighted signal intensity and to correlate it with the clinical and hormonal variables.

\section{Methods}

\section{Study design and setting}

Acromegaly patients, who were admitted to the Department of Endocrinology, at the Clinical Emergency County Hospital in Cluj-Napoca, Romania, between 2008 and 2015, were screened for inclusion in this observational, analytic, retrospective, cohort-type study.

\section{Participants}

Eighty-four patients with active or controlled acromegaly were included in the study. Of patients with hormonal deficits on other lines, only patients with properly substituted medication were selected. After excluding 53 patients (4 patients who underwent CT (computed tomography) scan for the diagnosis of the pituitary adenoma, 25 patients who did not have the initial MRI available for evaluation, 15 patients who did not undergo surgery, 3 patients who had mixed pituitary adenoma - secreting both $\mathrm{GH}$ and prolactin - and 6 patients whose diagnosis was not confirmed), 31 patients were included in the final study, with a mean age at diagnosis of $51.35 \pm 10.37$ years (age range, 27-73 years), of which 19 women (61.29\%) and 12 men (38.71\%). Data when given dopaminergic agonist treatment or GH antagonists and data after radiotherapy were excluded.

The clinical and biochemical data of the patients were obtained from the Department of Endocrinology database and patients' observational charts and the imagistic data were obtained from the Department of Radiology database.

The study protocol was designed in accordance with the ethical guidelines of the 1975 Declaration of Human Rights in Helsinki and was approved by the "Iuliu Haţieganu" University of Medicine and Pharmacy Ethics Committee.

\section{Clinical and demographic evaluation}

In all cases, the positive diagnosis of acromegaly was based on signs and symptoms of disease activity (ends undergoing expansion, arthralgia, asthenia, signs of pituitary tumor expansion: neuro-ophthalmic syndrome, headache, signs of pituitary insufficiency), on the biochemical demonstration of a non-suppressible GH on an OGTT (oral glucose tolerance test), concerning nadir GH $>1 \mathrm{ng} / \mathrm{ml}$ in non-diabetic patients or mean $\mathrm{GH} / 24$ hours $>2.5 \mathrm{ng} / \mathrm{ml}$ in diabetic patients, and an IGF-1 level above the age/sex-matched normal. There also have been cases of acromegaly with normal levels of IGF-1 and high levels of $\mathrm{GH}$. The imaging diagnosis was based on the presence of a pituitary adenoma on the MRI.

The following demographic data were recorded: sex, age, age at diagnosis, disease status and type of treatment (surgery, medical treatment with SSA - Sandostatin LAR (octreotide long acting release) or Somatuline PR (lanreotide prolonged-release).

\section{Imaging evaluation}

All subjects underwent MRI scans, on the same device, in a 1.5-T scanner (SIGNA Explorer MRI system - General Electric Medical Systems, United States). The examination before and after surgery was performed on the same device. The protocol included axial, sagittal, coronal T1 and T2 WI, and a gadolinium-enhanced T1sagittal and coronal sequences. The slice thickness was of $2 \mathrm{~mm}$, with 0.3 spacing. Post-surgical MRI follow-up was performed using sagittal and coronal $\mathrm{T} 1$ and $\mathrm{T} 2$, and gadolinium-enhanced T1-sagittal and coronal sequences. The slice thickness was of $2 \mathrm{~mm}$, with 0.3 spacing. In both cases, the MR examination FOV was focused only on the pituitary gland. The patients were investigated at diagnosis (31 patients), at 3 months ( 29 patients) and 12 months after neurosurgery (11 patients). The somatotropinomas were morphologically classified according to the T2-weighted signal as hypointense, hyperintense, or isointense by visual comparison with the normal pituitary tissue, or with the grey matter of the temporal lobe, when the pituitary tissue was not visible (Figure 1). 

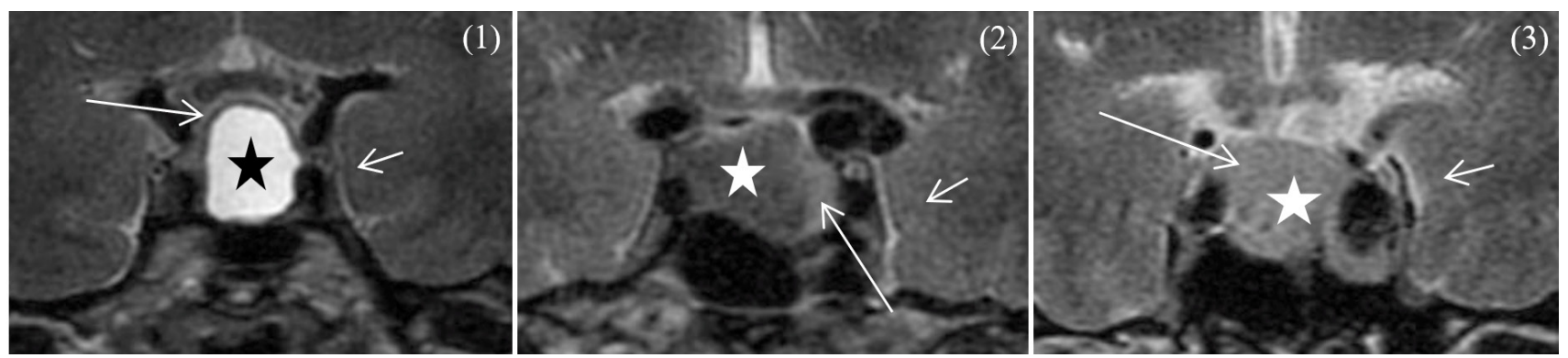

Figure 1. Classification of somatotropinomas according to the T2-weighted signal intensity (coronal views). Panel (1): T2-hyperintense somatotropinoma, panel (2): T2-hypointense somatotropinoma, panel (3): T2-isointense somatotropinoma, as compared to normal pituitary tissue (long arrowheads) and the cerebral grey matter of the temporal lobe (short arrowheads). The somatotropinomas are indicated by stars ( $\star$ - black or white for contrast)

Tumor volume was calculated using the formula $0.5 \mathrm{x}$ width $\mathrm{x}$ height $\mathrm{x}$ length [17]. Moreover, the tumors were classified in terms of invasion, according to Hardy's modified criteria, being graded from 1 to 4 : grade $1=$ microadenomas $(<10 \mathrm{~mm}$ diameter $)$, grade 2 $=$ macroadenomas $(>10 \mathrm{~mm}$ diameter, with or without suprasellar extension), grade $3=$ locally invasive tumors, with obvious bone destruction and the presence of the tumor in the sphenoid sinus and/or the cavernous sinuses, grade $4=$ tumors that extend cerebrally or extracranially, with or without metastases [18]. The lack of tumor relic was graded with 0 .

\section{Hormonal assays}

8 a.m. serum IGF-1 (ng/ml) level was measured by a chemo-luminescent immunometric assay, using an IMMULITE 1000 Analyzer (Siemens, Erlangen, Germany) (intraassay CV (coefficient of variation), $3.1-4.3 \%$; interassay $\mathrm{CV}, 5.8-8.4 \%$; calibration range, up to $1600 \mathrm{ng} / \mathrm{ml}$; analytical sensitivity, $20 \mathrm{ng} / \mathrm{ml}$ ). The different age/sex-matched normal ranges were excluded by expressing IGF-1 level as a percentage of the ULN (upper limit of the normal range) [2]. Serum GH level was measured by Diametra HGH ELISA kit (Segrate, Italy) (intraassay $\mathrm{CV}, 3.1-5.5 \%$; interassay $\mathrm{CV}, 4.5-7 \%$; analytical sensitivity, up to $0.105 \mu \mathrm{IU} / \mathrm{ml}$ ), using a STAT FAX 3200 Analyzer. Basal values of GH were used, in order to overcome GH changing methodology for diabetic or non-diabetic patients.

\section{Statistical evaluation}

The statistical analysis was performed using $\mathrm{R}$ version 3.2.3 (2015-12-10). Normal distribution of continuous numeric variables was assessed with ShapiroWilk test and quantile-quantile plots. Quantitative variables were expressed as mean $\pm \mathrm{SD}$ (standard deviation), if normally distributed, and as median $\left(25^{\text {th }}-75^{\text {th }}\right.$ percentile), if not. Categorical variables were expressed as percentage and counts. Chi-square and Fisher exact tests were used in order to analyze the differences between independent groups of categorical variables. Comparisons between groups of quantitative variables were performed using Student $t$ test for independent variables (when comparing two groups of normally distributed variables) and using ANOVA test (when comparing three or more groups of normally distributed variables). In case of abnormally distributed variables, the Mann-Whitney U test was used (in order to compare two variables) and the Kruskal-Wallis test (to compare three or more variables). The relationship between quantitative variables was characterized using Spearman correlation coefficient. Repeated measures quantitative variables were compared with the Wilcoxon signed ranks test (for two measurements) and Friedman test (for more than two measurements). Linear mixed models with Laplace approximation were used to compare independent groups regarding repeated measures quantitative variables. A value of $p<0.05$ was considered to have statistical significance and for all tests the twotailed p-value was used.

\section{Results \\ Patient characteristics}

There was a $41.94 \%$ increase in the number of patients diagnosed between 2012 and 2015 ( $\mathrm{n}=22)$ compared to those diagnosed between 2008 and 2011 $(n=9), p=0.020$. There were statistically significant differences between men and women according to the age at diagnosis $(\mathrm{p}=0.027)$, men having an earlier diagnosis. However, there were no statistically significant differences regarding the tumor volume at diagnosis $(\mathrm{p}=0.326)$, and also the median IGF-1 level and median GH basal level were similar. When we compared macroadenomas with microadenomas we found a statistically significant difference regarding $\mathrm{GH}(\mathrm{p}=0.012)$ (Table I). 
Table I. Baseline characteristics at diagnosis (31 patients).

\begin{tabular}{|c|c|c|c|c|c|c|c|c|c|c|}
\hline Baseline characteristics & Women & Men & $\mathbf{p}$ & $\begin{array}{c}\text { Macro- } \\
\text { adenoma }\end{array}$ & $\begin{array}{c}\text { Micro- } \\
\text { adenoma }\end{array}$ & p & $\begin{array}{l}\text { Hyper- } \\
\text { intense }\end{array}$ & $\begin{array}{l}\text { Hypo- } \\
\text { intense }\end{array}$ & Iso-intense & $\mathbf{p}$ \\
\hline Number (\%) & $19(61.29)$ & $12(38.71)$ & - & $22(70.97)$ & $9(29.03)$ & - & $9(29.03)$ & $16(51.61)$ & $6(19.35)$ & - \\
\hline Age (years), mean (SD) & $54.58(7.6)$ & $\begin{array}{l}46.25 \\
(12.36)\end{array}$ & 0.027 & $\begin{array}{c}50.73 \\
(10.77)\end{array}$ & $\begin{array}{l}52.89 \\
(9.78)\end{array}$ & 0.607 & $\begin{array}{c}50.22 \\
(15.14)\end{array}$ & $51(6.9)$ & $54(11.19)$ & 0.784 \\
\hline IGF-1 (\% ULN), mean (SD) & $786.36(286.62)$ & $\begin{array}{c}971.94 \\
(398.69)\end{array}$ & 0.142 & $\begin{array}{c}929.98 \\
(331.68)\end{array}$ & $\begin{array}{c}682.74 \\
(312.21)\end{array}$ & 0.066 & $\begin{array}{c}884.93 \\
(254.83)\end{array}$ & $\begin{array}{c}884.38 \\
(398.95)\end{array}$ & $\begin{array}{c}748.28 \\
(311.01)\end{array}$ & 0.693 \\
\hline Basal GH (ng/ml)* & $\begin{array}{c}14.3 \\
(5.54-19.25)\end{array}$ & $\begin{array}{c}13.55 \\
(3.55-21.4)\end{array}$ & 0.952 & $\begin{array}{c}16.6 \\
(9.61-21.23)\end{array}$ & $\begin{array}{c}5.62 \\
(3.17-6.24)\end{array}$ & 0.012 & $\begin{array}{c}6.24 \\
(5.27-12)\end{array}$ & $\begin{array}{c}15.7 \\
(8.7-23.1)\end{array}$ & $\begin{array}{c}11.58 \\
(5.58-17.28)\end{array}$ & 0.405 \\
\hline $\begin{array}{l}\text { Type of adenoma: } \\
\text {-Macroadenoma; } \\
\text { number }(\%) \\
\text {-Microadenoma; } \\
\text { number (\%) }\end{array}$ & $\begin{array}{c}13(68.42) \\
6(31.58)\end{array}$ & $\begin{array}{l}9(75.00) \\
3(25.00)\end{array}$ & 1 & & & & $\begin{array}{l}6(66.67) \\
3(33.33)\end{array}$ & $\begin{array}{l}11(68.75) \\
5(31.25)\end{array}$ & $\begin{array}{l}5(83.33) \\
1(16.67)\end{array}$ & 0.769 \\
\hline $\begin{array}{l}\text { T2-weighted MRI adenoma } \\
\text { intensity: } \\
\text {-Hyperintense; number (\%) } \\
\text {-Hypointense; number (\%) } \\
\text {-Isointense; number (\%) }\end{array}$ & $\begin{array}{l}6(31.58) \\
8(42.11) \\
5(26.32)\end{array}$ & $\begin{array}{c}3(25) \\
8(66.67) \\
1(8.33)\end{array}$ & 0.39 & $\begin{array}{c}6(27.27) \\
11(50) \\
5(22.73)\end{array}$ & $\begin{array}{l}3(33.33) \\
5(55.56) \\
1(11.11)\end{array}$ & 0.769 & & & & \\
\hline Tumor volume $\left(\mathrm{cm}^{3}\right)^{*}$ & $\begin{array}{c}0.81 \\
(0.25-3.85)\end{array}$ & $\begin{array}{c}1.3 \\
(0.46-5.22)\end{array}$ & 0.326 & & & & $\begin{array}{c}1.64 \\
(0.25-5.82)\end{array}$ & $\begin{array}{c}0.69 \\
(0.31-4.48)\end{array}$ & $\begin{array}{c}1.37 \\
(0.34-2.36)\end{array}$ & 0.939 \\
\hline $\begin{array}{l}\text { Hardy classification: } \\
-1 \text {; number }(\%) \\
-2 \text {; number }(\%) \\
-3 \text {; number }(\%) \\
-4 \text {; number }(\%)\end{array}$ & $\begin{array}{c}4(21.1) \\
7(36.8) \\
8(42.1) \\
0(0.0)\end{array}$ & $\begin{array}{c}2(16.7) \\
4(33.3) \\
5(41.7) \\
1(8.3)\end{array}$ & 0.770 & $\begin{array}{c}0(0.0) \\
9(40.9) \\
12(54.5) \\
1(4.5)\end{array}$ & $\begin{array}{l}6(66.7) \\
2(22.2) \\
1(11.1) \\
0(0.0)\end{array}$ & $<0.001$ & $\begin{array}{l}2(22.2) \\
3(33.3) \\
3(33.3) \\
1(11.1)\end{array}$ & $\begin{array}{c}3(18.8) \\
5(31.2) \\
8(50.0) \\
0(0.0)\end{array}$ & $\begin{array}{c}1(16.7) \\
3(50.0) \\
2(33.3) \\
0(0.0)\end{array}$ & 0.863 \\
\hline
\end{tabular}

Legend: Results are presented as mean $\pm \mathrm{SD}$, if not stated otherwise; *median (interquartile range Q1 - Q3); ULN, upper limit of the normal range.

In T2-weighted sequences, the somatotropinomas were hypointense in 16 cases $(51.61 \%)$, but no relationships were found between T2-weighted signal and IGF-1, basal GH levels or tumor volume (Table I). Concerning the surgery type, the transsphenoidal approach was used on 27 patients $(87 \%)$, while the transcranial approach was used on 3 patients $(9.78 \%)$, and only 1 patient $(3.22 \%)$ had transsphenoidal, followed by transcranial surgery. Of all patients only one patient had total resection of the pituitary adenoma, while the rest had partial resection. At the 3 months MRI evaluation after surgery, 10 (32.26\%), had no tumor, while 19 had partial resection (5 (16.13\%) had hyperintense adenomas, 11 (35.48\%) had hypointense adenomas, 3 (9.68\%) had isointense adenomas), while 2 did not underwent the investigation. At the 12 months MRI evaluation after surgery, 7 (35\%), had no tumor, while 4 had partial resection (1 (5\%) had hyperintense adenomas, $2(10 \%)$ had hypointense adenomas, $1(5 \%)$ had isointense adenomas), while 9 did not underwent the investigation and 11 were excluded due to radiotherapy intervention. At the 3 months assessment we found 10 patients without tumor relic, and 19 patients with incomplete surgery: 5 hyperintense, 11 hypointense and 3 isointense [2.05 $(0.04-3.6), 0.35(0.24-2.65), 0.294$ $(0.16-2.04) \mathrm{cm} 3$ - no statistically significant differences were found, $\mathrm{p}=0.884]$.

\section{Tumor and hormonal characteristics}

Considering the hormonal evolution according to size, there was a statistically significant decrease of both IGF-1 and GH levels in macroadenomas $(\mathrm{p}<0.001$, $\mathrm{p}<0.001$, respectively), and only of GH in microadenomas $(\mathrm{p}=0.010)$. Regarding the hormonal evolution, according to T2-weighted MRI, both IGF-1 and GH, decreased significantly, in hypointense somatotropinomas $(\mathrm{p}=0.013, \mathrm{p}<0.001$, respectively), while in hyperintense somatotropinomas only IGF-1 levels decreased significantly $(p=0.011)$. We did not observe a significant decrease of IGF-1, and GH in isointense somatotropinomas (Table II). We did not observe a statistically significant relationship between the decrease of IGF-1 and the treatment with Somatuline PR $(\mathrm{p}=0.531)$ in comparison with the treatment with Sandostatin LAR ( $p=0.004)$, whereas the GH decrease was significant for both SSA analogs (Table III).

A significant statistic correlation was found between IGF-1 or GH levels and tumor volume before surgery (Spearman $=0.38, \quad \mathrm{p}<0.001 ; \quad$ Spearman $=0.64$, $\mathrm{p}<0.001$, respectively) and after surgery (Spearman $=0.61$, $\mathrm{p}=0.001$; Spearman $=0.74, \mathrm{p}<0.001$, respectively), but no statistically significant relationship was found between the hormonal parameters and the tumor volume after 1 year with SSA treatment. 
Table II. Evolution of IGF-1 and basal GH according to size and T2-weighted intensity on MRI (31 patients).

\begin{tabular}{|c|c|c|c|c|c|c|c|}
\hline Parameter & Type of adenoma & At diagnosis & After surgery & $\begin{array}{l}\text { After } 3 \text { months } \\
\text { with SSA }\end{array}$ & $\begin{array}{c}\text { After } 6 \text { months } \\
\text { with SSA }\end{array}$ & $\begin{array}{l}\text { After } 12 \text { months } \\
\text { with SSA }\end{array}$ & p-value* \\
\hline \multirow{3}{*}{$\begin{array}{l}\text { IGF-1 } \\
(\% \text { ULN) }\end{array}$} & Macroadenoma & $\begin{array}{c}346.9 \\
(279.82-496.53)\end{array}$ & $\begin{array}{c}220.56 \\
(160.83-340.92)\end{array}$ & $\begin{array}{c}227.11 \\
(135.27-261.44)\end{array}$ & $\begin{array}{c}140.33 \\
(122.67-267.05)\end{array}$ & $\begin{array}{c}106.37 \\
(73.03-123.22)\end{array}$ & $<0.001$ \\
\hline & Microadenoma & $\begin{array}{c}335.74 \\
(154.66-360.91)\end{array}$ & $\begin{array}{c}156.6 \\
(99.15-270.41)\end{array}$ & $\begin{array}{c}77 \\
(47.81-192.93)\end{array}$ & $\begin{array}{c}123.52 \\
(69.48-152.97)\end{array}$ & $\begin{array}{c}97.16 \\
(84.41-271.82)\end{array}$ & 0.066 \\
\hline & $\mathrm{p}$-value** & & & $<0.001$ & & & \\
\hline \multirow{3}{*}{$\begin{array}{l}\text { Basal GH } \\
(\mathrm{ng} / \mathrm{ml})\end{array}$} & Macroadenoma & $\begin{array}{c}16.6 \\
9.34-21.5)\end{array}$ & $\begin{array}{c}5.17 \\
(2.06-14.2)\end{array}$ & $\begin{array}{c}4.82 \\
(3.57-9.51)\end{array}$ & $\begin{array}{c}6.31 \\
(1.42-16.62)\end{array}$ & $\begin{array}{c}1.46 \\
(1.31-4.75)\end{array}$ & $<0.001$ \\
\hline & Microadenoma & $\begin{array}{c}5.62 \\
(3.07-8.53)\end{array}$ & $\begin{array}{c}2.51 \\
(1.48-3.86)\end{array}$ & $\begin{array}{c}0.89 \\
(0.72-3.37)\end{array}$ & $\begin{array}{c}1.2 \\
(1.09-1.86)\end{array}$ & $\begin{array}{c}2.02 \\
(1.89-3.33)\end{array}$ & 0.010 \\
\hline & p-value** & & & $>0.05$ & & & \\
\hline \multirow{4}{*}{$\begin{array}{l}\text { IGF-1 (\% } \\
\text { ULN) }\end{array}$} & Hyperintense & $\begin{array}{c}337.82 \\
(331.2-369.33)\end{array}$ & $\begin{array}{c}270.41 \\
(171-297.38)\end{array}$ & $\begin{array}{c}105.73 \\
(67.25-149.07)\end{array}$ & $\begin{array}{c}123.52 \\
(84.74-159.91)\end{array}$ & $\begin{array}{c}101.76 \\
(87.59-119)\end{array}$ & 0.011 \\
\hline & Hypointense & $\begin{array}{c}355.28 \\
(272.08-440.87)\end{array}$ & $\begin{array}{c}184.11 \\
(137.75-371.02)\end{array}$ & $\begin{array}{c}233.38 \\
(193.28-256.61)\end{array}$ & $\begin{array}{c}140.33 \\
(122.67-229.18)\end{array}$ & $\begin{array}{c}148.73 \\
(75.88-257.12)\end{array}$ & 0.013 \\
\hline & Isointense & $\begin{array}{c}309.35 \\
(212.82-357.39)\end{array}$ & $\begin{array}{c}171.55 \\
(111.47-232.35)\end{array}$ & $\begin{array}{c}137.73 \\
(92.77-297.63)\end{array}$ & $\begin{array}{c}189.18 \\
(121.4-256.96)\end{array}$ & $\begin{array}{c}89.3 \\
(75.65-102.95\end{array}$ & 0.308 \\
\hline & p-value** & & & $>0.05$ & & & \\
\hline \multirow{4}{*}{$\begin{array}{l}\text { Basal GH } \\
(\mathrm{ng} / \mathrm{ml})\end{array}$} & Hyperintense & $\begin{array}{c}6.24 \\
(4.65-13.95)\end{array}$ & $\begin{array}{c}2.85 \\
(2.27-10.51)\end{array}$ & $\begin{array}{c}0.59 \\
(0.59-2.68)\end{array}$ & $\begin{array}{c}1.07 \\
(1.06-5.2)\end{array}$ & $\begin{array}{c}1.58 \\
(1.53-2.98)\end{array}$ & 0.084 \\
\hline & Hypointense & $\begin{array}{c}15.7 \\
(12.35-24.7)\end{array}$ & $\begin{array}{c}4.03 \\
(0.76-11.43)\end{array}$ & $\begin{array}{c}4.37 \\
2.85-8.74)\end{array}$ & $\begin{array}{c}2.47 \\
(0.96-13.06)\end{array}$ & $\begin{array}{c}1.74 \\
(1.46-5.23)\end{array}$ & $<0.001$ \\
\hline & Isointense & $\begin{array}{c}11.58 \\
(5.45-17.3)\end{array}$ & $\begin{array}{c}3.87 \\
(2.06-4.98)\end{array}$ & $\begin{array}{c}7.11 \\
(7.74-9)\end{array}$ & $\begin{array}{c}4.12 \\
(1.94-6.31)\end{array}$ & $\begin{array}{c}2.9 \\
(1.42-4.38)\end{array}$ & 0.308 \\
\hline & p-value** & & & $>0.05$ & & & \\
\hline
\end{tabular}

Legend: Results are presented as median (interquartile range Q1 - Q3); * - within group comparison; ** - between groups for repeated measures comparison; ULN, upper limit of the normal range.

Table III. Evolution of IGF-1 and basal GH accordind to the type of SSA (Sandostatin LAR or Somatuline PR) (31 patients).

\begin{tabular}{|c|c|c|c|c|c|c|}
\hline Parameter & Type of SSA & After surgery & $\begin{array}{c}\text { After } 3 \text { months } \\
\text { with SSA }\end{array}$ & $\begin{array}{l}\text { After } 6 \text { months } \\
\text { with SSA }\end{array}$ & $\begin{array}{l}\text { After } 12 \text { months } \\
\text { with SSA }\end{array}$ & p-value * \\
\hline \multirow{3}{*}{$\begin{array}{l}\text { IGF-1 } \\
(\% \text { ULN) }\end{array}$} & Sandostatin LAR & $\begin{array}{c}260.21 \\
(173.1-352.36)\end{array}$ & $\begin{array}{c}223.49 \\
(120.09-256.62)\end{array}$ & $\begin{array}{c}140.33 \\
(84.74-209.36)\end{array}$ & $106.37(71.47-168.12)$ & 0.004 \\
\hline & Somatuline PR & $\begin{array}{c}157.86 \\
(151.35-162.56)\end{array}$ & $\begin{array}{c}121.47 \\
(80.2-157.2)\end{array}$ & $\begin{array}{c}123.52 \\
(123-159.91)\end{array}$ & $97.16(90.8-188.54)$ & 0.531 \\
\hline & $\mathrm{p}$ & 0.056 & 0.233 & 0.849 & 0.659 & \\
\hline \multirow{3}{*}{$\begin{array}{l}\text { Basal GH } \\
(\mathrm{ng} / \mathrm{ml})\end{array}$} & Sandostatin LAR & $\begin{array}{c}5.21 \\
(2.76-13.22)\end{array}$ & $\begin{array}{c}4.82 \\
(2.55-8.35)\end{array}$ & $\begin{array}{c}2.47 \\
(1.07-14.9)\end{array}$ & $1.64(1.22-4.48)$ & $<0.001$ \\
\hline & Somatuline PR & $\begin{array}{c}2.01 \\
(0.99-2.5)\end{array}$ & $\begin{array}{c}0.54 \\
(0.38-0.71)\end{array}$ & $\begin{array}{c}1.06 \\
(0.2-1.2)\end{array}$ & $1.53(0.84-2.25)$ & 0.038 \\
\hline & $\mathrm{p}$ & 0.027 & 0.07 & 0.153 & 0.555 & \\
\hline
\end{tabular}

Legend: Results are presented as median (interquartile range Q1 - Q3); * - within group comparison; ** - between groups comparison; ULN, upper limit of the normal range.

The percentage of optimally controlled patients increased from $12.9 \%$ after surgery, to $26.66 \%$ after 3 months, to $28.57 \%$ after 12 months with somatostatin analogs, while the percent of uncontrolled patients decreased from $58.07 \%$ after surgery, to $53.35 \%$ after 3 months, to $28.58 \%$ after 12 months with SSA analogs (Figure 2). In terms of T2-weighted MRI intensity the highest percentage of optimally controlled patients with SSA treatment was in hypointense somatotropinomas $(50 \%)$, followed by hyperintense $(42.85 \%)$ and isointense (7.15\%) somatotropinomas (Figure 3 ).
Optimally controlled acromegaly in terms of drug and surgical therapy was defined as: controlled symptomatology, nadir $\mathrm{GH}<1 \mathrm{ng} / \mathrm{ml}$ on OGTT or mean GH/ 24 hours $<$ $2.5 \mathrm{ng} / \mathrm{ml}$ and normal levels of IGF-1 age/sex-matched. In cases of discordance between GH and IGF-1, the decision concerning acromegaly activity was made according to clinical signs. Partially controlled acromegaly was defined as: controlled symptomatology, nadir $\mathrm{GH}>1 \mathrm{ng} / \mathrm{ml}$ on OGTT or mean $\mathrm{GH} / 24$ hours $>2.5 \mathrm{ng} / \mathrm{ml}$, which reduced more than $50 \%$ to the level at diagnosis, and high level of IGF-1, which reduced more than $50 \%$ to the level at diagnosis. 


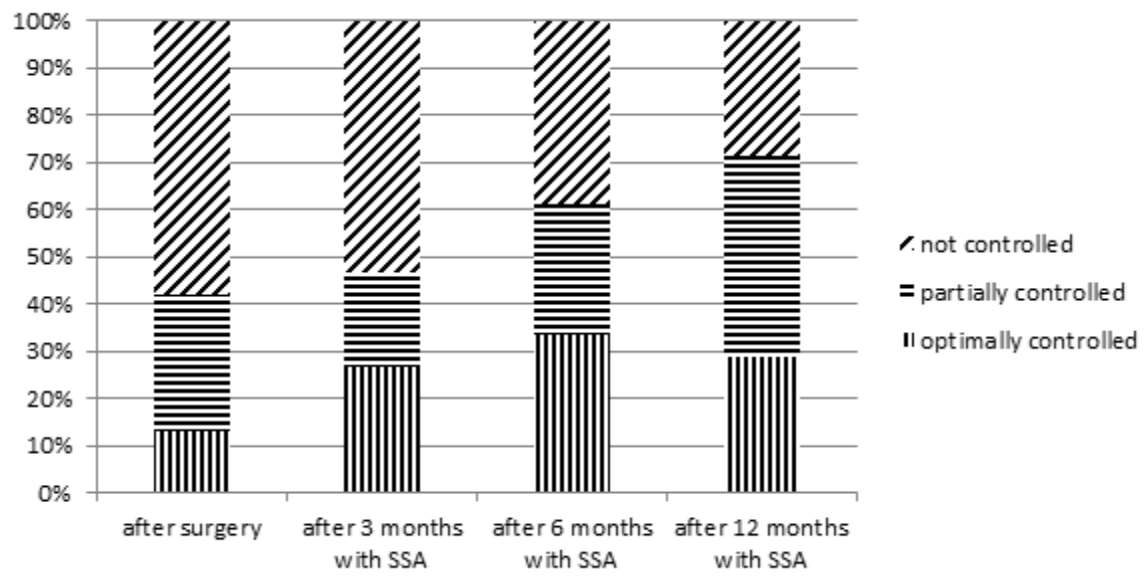

Figure 2. Type of control after surgery and after treatment with SSA (31 patients).

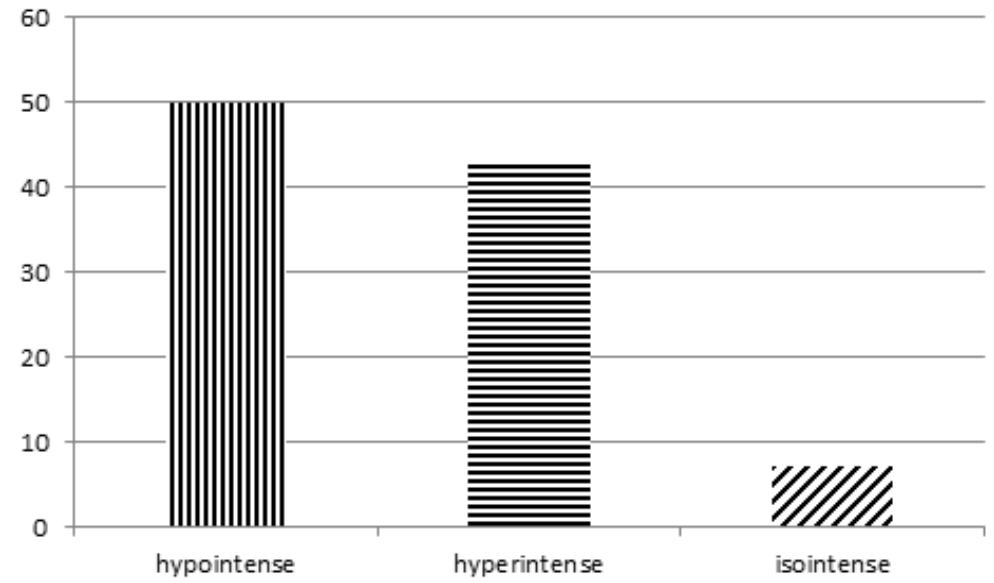

Figure 3. Percentage of patients who achieved optimally hormonal control according to T2-weighted MRI signal intensity.

Uncontrolled acromegaly was defined as: specific symptomatology for active acromegaly, nadir GH $>1 \mathrm{ng} /$ $\mathrm{ml}$ on OGTT or mean $\mathrm{GH} / 24$ hours $>2.5 \mathrm{ng} / \mathrm{ml}$, which did not reduce more than $50 \%$ to the level at diagnosis, and high level of IGF-1, which did not reduce more than $50 \%$ to the level at diagnosis. Regarding the drug control, this was established when achieving correspondent values at the highest dose of somatostatin analogs $(30 \mathrm{mg}$ for Sandostatin LAR and $120 \mathrm{mg}$ for Somatuline PR).

\section{Discussion}

This study was carried out in order to address the therapeutic response of somatotropinomas after surgery and after long-term treatment with somatostatin analogs, in terms of T2-weighted MRI features. Given the fact that this topic has recently come to researchers' attention, few studies have been published having as main topic the long-term follow-up of acromegalic patients after incomplete surgery.

It is widely accepted that the majority of somatotropinomas are macroadenomas $(70.97 \%$ in our study), the percentage of microadenomas $(29.03 \%)$ being similar to the $30 \%$, higher than the $22.5 \%$, and lower than the $84 \%$ found in other studies $[2,19,20]$. Moreover, we detected a higher secretion of GH in macroadenomas compared to microadenomas, most probably due to the higher tumor volume in the first case. Furthermore, the tumor volume at diagnosis was higher in T2-hyperintense somatotropinomas than in T2-hypo- or isointense somatotropinomas, this being an indicative of a higher proliferative status [2]. 
We detected a high prevalence of T2-hypointense somatotropinomas, representing $51.61 \%$ of the cases, similar to the ones reported previously by Potorac et al. [2,21] and Antunes et al. [20] and higher than the 27\% recorded by Heck et al. [11], or the $40 \%$ recorded by PuigDomingo et al. [16], and lower than $72.7 \%$, reported by Tortora et al [22]. The percentage of hyperintense and isointense somatotropinomas was relatively equal in our series $(29.03 \%$ versus $19.35 \%)$, also similar to the ones reported by Potorac et al. [2]. These proportions may be due to the way we defined the T2-weighted signal intensity, by visually comparing it to the normal pituitary tissue, or the temporal grey matter, when no normal pituitary tissue was visible. In other studies, T2-hypo- and hyper-intensity were also visually defined, but as being lower than that of the white matter, or higher than that of the grey matter, respectively, while T2-iso-intensity as the range between the two signals $[11,16,20,23]$. In the study of Shen et al. the T2-intensity was quantitatively assessed by measuring the rSI (relative signal intensity) on T1- and T2-weighted MRI, by comparing it to the white matter of the frontal lobe [4]. Given the fact that the white matter has similar intensity to that of the normal pituitary tissue only on T1-weighted sequences, and not on T2-weighted sequences, we believe that future studies should take into consideration the comparison of pituitary adenomas with the normal pituitary tissue, when possible.

We detected a $41.94 \%$ increase in the number of patients diagnosed between 2012-2015, compared to those diagnosed 4 years earlier, but this was probably not due to an increase in the incidence or prevalence of acromegaly, the total prevalence ranging between 2.8-13.7 cases $/ 100,000$ people and the annual incidence ranging between 0.2-1.1 cases/100,000 people [24], but more likely due to improving diagnostic methods and increasing patient addressability to the Department of Endocrinology in Cluj-Napoca.

Our results also show that the responsiveness to SSA treatment can be predicted by the T2-weighted MRI signal, the therapeutic response to SSA usually being seen in more than $50 \%$ of patients [25]. The physiological basis of this responsiveness in acromegaly is related to the phenotype, distribution and proportion of the somatostatin receptors (SSR) of the somatotropinoma, especially of SSR2 and SSR5 [16]. Unfortunately, we were not able to determine the presence of these receptors, which is why we only presume that, in our study, the significant decrease of IGF-1 and GH levels in T2-hypointense somatotropinomas is due to the presence of a higher proportion of SSR than in T2-weighted hyper- or isointense somatotropinomas. A significant decrease of IGF-1 was observed only in hyperintense somatotropinomas, our results being similar to those of Puig-Domingo et al. who obtained $20 \%$ control of the disease in hyperintese somatotropinomas [16]. We also observed that IGF-1 and GH levels significantly decreased in both macro- and microadenomas, excepting GH level in microadenomas, which had an increase after 3 months with somatostatin analogs. Probably the small number of patients and the exclusion of data when given adjuvant treatment did not allow us to obtain significant results.

Comparing the results in relation to medical treatment, we observed that the efficacy in reducing GH secretion was statistically significant for both Sandostatin LAR and Somatuline PR, but IGF-1 levels were reduced only by Sandostatin LAR. Our results are in agreement with Freda et al., who have shown that, in patients who were not selected for prior SSA responsiveness, the efficacy of Sandostatin LAR was greater than that of Somatuline PR [25].

In opposition with the results reported by BaldysWaligorska et al. [26], and in accordance with the results reported by Krzentowska-Korek et al. [27], we detected a positive statistically significant correlation between the tumor volume and GH or IGF-1 levels prior to and after surgery. Moreover, the high level of GH before and after surgery correlated better than IGF-1 with tumor volume, suggesting that $\mathrm{GH}$ level in acromegalic patients is a more sensitive sign of high tumor volume than IGF-1 [28]. This may be due to the fact that IGF-1 is an indirect marker of GH secretion, being influenced by weight, hyperglycemia, insulin concentration and IGF-1 binding proteins, while $\mathrm{GH}$ is determined only by the secretory status of the somatotropinoma [14].

An optimally controlled acromegaly (defined by controlled symptomatology, normalized IGF-1 level, nadir $\mathrm{GH}<1 \mathrm{ng} / \mathrm{ml}$ on OGTT or mean GH/24 hours $<2.5 \mathrm{ng} /$ $\mathrm{ml}$ ) was detected in $50 \%$ hypointense somatotropinomas, as compared to $42.85 \%$ hyperintense somatotropinomas and $7.15 \%$ isointense somatotropinomas, lower than the response found in other studies $[4,16]$. This might be due to the fact that our criteria for defining optimally controlled acromegaly was much stricter and comprised both GH and IGF-1 levels, while in the studies mentioned above, the full response rate was defined only as normalized IGF-1 level. Nevertheless, in both cases, the higher proportion of optimally controlled patients was observed in hypointense somatotropinomas. Moreover, we observed that the percentage of optimally controlled patients did not increase significantly during the SSA treatment (from $26.66 \%$ after 3 months, to $28.57 \%$ after 12 months). This may be due to the small number of patients included in the study and possibly to the fact that patients' data when given combined medical treatment or radiotherapy was excluded.

The potential limitations encountered in our study derive from the fact that a small number of patients was included, the study design was a retrospective cohort type one and the classification of somatotropinomas in hypo-, hyper-, or iso-intense in T2-weighted MRI was performed visually and not quantitatively. A new method of evaluating 
the T2-weighted signal intensity on the MRI has been developed lately: the machine learning (ML)-based highdimensional quantitative texture analysis (qTA), which evaluates lesion pattern that may not be visible. According to the authors' results it may have the potential of better predicting the response to SSA therapy and may have a better performance than the qualitative and quantitative T2weighted rSI [23]. As a result, this may represent the future in evaluating the characteristics of somatotropinomas according to the T2-weighted signal intensity on the MRI, but more studies need to be conducted.

\section{Conclusions}

Our results show that the percentage of optimally controlled patients increased within one year of follow-up. We have also observed that the tumor volume correlates with the hormonal secretion of the somatotropinomas and the T2-weighted signal intensity could help classify the somatotropinomas in a hypointense group with a better therapeutic response after surgery and after long-term treatment with somatostatin analogs.

\section{Acknowledgements}

The MRI images are published with the courtesy of Professor Dudea Sorin, MD, PhD, from the Department of Radiology, Clinical Emergency County Hospital in Cluj-Napoca, Iuliu Hatieganu University of Medicine and Pharmacy, Cluj-Napoca, Romania.

The demographic and hormonal data were taken from the Department of Endocrinology database and the patients' charts by courtesy of senior lecturers Ana Valea, $\mathrm{MD}, \mathrm{PhD}$ and Alina Silaghi, MD, PhD.

\section{References}

1. Dumitrache C. Part II. Acromegaly Adult Hypersomatotropism. In: Borzea V, Samoilescu R (eds). Endocrinologie clinica [Clinical Endocrinology]. $3^{\text {rd }}$ Edition. Bucharest: National; 2012: p. 251-267 (Romanian)

2. Potorac I, Petrossians P, Daly AF, Schillo F, Ben Slama C, Nagi S, et al. Pituitary MRI characteristics in 297 acromegaly patients based on T2-weighted sequences. Endocr Relat Cancer. 2015;22:169-177.

3. Maffezzoni F, Frara S, Doga M, Mazziotti G, Giustina A. New medical therapies for acromegaly. Growth Horm IGF Res. 2016;30-31:58-63.

4. Shen M, Zhang Q, Liu W, Wang M, Zhu J, Ma Z, et al. Predictive value of $\mathrm{T} 2$ relative signal intensity for response to somatostatin analogs in newly diagnosed acromegaly. Neuroradiology. 2016; 58: 1057-1065.

5. Pokrajac C, Claridge AG, Shakoor SK, Trainer PJ. The octreotide test dose is not a reliable predictor of the subsequent response to somatostatin analogue therapy in patients with acromegaly. Eur J Endocrinol. 2006;154:267-274.
6. Hagiwara $\mathrm{A}$, Inoue $\mathrm{Y}$, Wakasa $\mathrm{K}$, Haba $\mathrm{T}$, Tashiro $\mathrm{T}$, Miyamoto T. Comparison of growth hormone-producing and non-growth hormone-producing pituitary adenomas: imaging characteristics and pathologic correlation. Radiology. 2003;228:533-538.

7. Katznelson L, Laws ER Jr, Melmed S, Molitch ME, Murad $\mathrm{MH}, \mathrm{Utz} \mathrm{A}$, et al. Acromegaly: an endocrine society clinical practice guideline. J Clin Endocrinol Metab. 2014;99:39333951.

8. Buchfelder M, Schlaffer SM. The surgical treatment of acromegaly. Pituitary. 2017;20:76-83.

9. Katznelson L. An update on treatment strategies for acromegaly. Expert Opin Pharmacother. 2008;9:22732280.

10. Heck A, Emblem KE, Casar-Borota O, Ringstad G, Bollerslev J. MRI T2 characteristics in somatotroph adenomas following somatostatin analog treatment in acromegaly. Endocrine. 2016;53:327-330.

11. Heck A, Ringstad G, Fougner SL, Casar-Borota O, Nome $\mathrm{T}$, Ramm-Pettersen J, et al. Intensity of pituitary adenoma on T2-weighted magnetic resonance imaging predicts the response to octreotide treatment in newly diagnosed acromegaly. Clin Endocrinol (Oxf). 2012;77:72-78.

12. Bacigaluppi S, Gatto F, Anania P, Bragazzi NL, Rossi DC, Benvegnu $\mathrm{G}$, et al. Impact of pre-treatment with somatostatin analogs on surgical management of acromegalic patients referred to a single center. Endocrine. 2015;51:524-533.

13. Fougner SL, Bollerslev J, Svartberg J, Øksnes M, Cooper J, Carlsen SM. Preoperative octreotide treatment of acromegaly: long-term results of a randomised controlled trial. Eur J Endocrinol. 2014;171:229-235.

14. Heck A, Emblem KE, Casar-Borota O, Bollerslev J, Ringstad G. Quantitative analyses of T2-weighted MRI as a potential marker for response to somatostatin analogs in newly diagnosed acromegaly. Endocrine. 2016;52:333343.

15. Fougner SL, Casar-Borota O, Heck A, Berg JP, Bollerslev J. Adenoma granulation pattern correlates with clinical variables and effect of somatostatin analogue treatment in a large series of patients with acromegaly. Clin Endocrinol (Oxf). 2012;76:96-102.

16. Puig-Domingo M, Resmini E, Gomez-Anson B, Nicolau J, Mora M, Palomera E, et al. Magnetic resonance imaging as a predictor of response to somatostatin analogs in acromegaly after surgical failure. J Clin Endocrinol Metab. 2010;95:4973-4978.

17. Lundin P, Pedersen F. Volume of pituitary macroadenomas: assessment by MRI. J Comput Assist Tomogr. 1992;16:519528.

18. Vieria Neto L, Wildemberg LE, Colli LM, Kasuki L, Marques NV, Moraes AB, et al. ZAC1 and SSTR2 are downregulated in non-functioning pituitary adenomas but not in somatotropinomas. PLoS One. 2013;8:e77406.

19. Petrossians P, Tichomirowa MA, Stevenaert A, Martin D, Daly AF, Beckers A. The Liege Acromegaly Survey (LAS): a new software tool for the study of acromegaly. Ann Endocrinol (Paris). 2012;73:190-201. 
20. Antunes X, Ventura N, Camilo GB, Wildemberg LE, Guasti A, Pereira PJM, et al. Predictors of surgical outcome and early criteria of remission in acromegaly. Endocrine. 2018;60:415-422.

21. Potorac I, Beckers A, Bonneville JF. T2-weighted MRI signal intensity as a predictor of hormonal and tumoral responses to somatostatin receptor ligands in acromegaly: a perspective. Pituitary. 2017;20:116-120.

22. Tortora F, Negro A, Grasso LFS, Colao A, Pivonello R, Splendiani A, et al. Pituitary magnetic resonance imaging predictive role in the therapeutic response of growth hormone-secreting pituitary adenomas. Gland Surg. 2019;8(Suppl 3):S150-S158.

23. Kocak B, Durmaz ES, Kadioglu P, Polat Korkmaz O, Comunoglu N, Tanriover N, et al. Predicting response to somatostatin analogues in acromegaly: machine learningbased high-dimensional quantitative texture analysis on T2-weighted MRI. Eur Radiol. 2019;29:2731-2739.
24. Lavrentaki A, Paluzzi A, Wass JA, Karavitaki N. Epidemiology of acromegaly: review of population studies. Pituitary. 2017;20:4-9.

25. Freda PU, Katznelson L, van der Lely AJ, Reyes CM, Zhao S, Rabinowitz D. Long-acting somatostatin analog therapy of acromegaly: a meta-analysis. J Clin Endocrinol Metab. 2005;90:4465-4473.

26. Bałdys-Waligórska A, Krzentowska-Korek A, Gołkowski F, Sokołowski G, Hubalewska-Dydejczyk A. The predictive value of the IGF-1 level in acromegaly patients treated by surgery and a somatostatin analogue. Endokrynol Pol. 2011;62:401-408.

27. Krzentowska-Korek A, Gołkowski F, Bałdys-Waligórska A, Hubalewska-Dydejczyk A. Efficacy and complications of neurosurgical treatment of acromegaly. Pituitary. 2011;14:157-162.

28. Rieger A, Rainov NG, Ebel H, Sanchin L, Shibib K, Helfrich $\mathrm{C}$, et al. Factors predicting pituitary adenoma invasiveness in acromegalic patients. Neurosurg Rev. 1997;20:182-187. 